\title{
Narcissism: A factor behind the selective sharing of news online
}

\author{
George J. D. Sweeten \\ Northumbria University \\ Newcastle upon Tyne, UK \\ george.sweeten@northumbria.ac.uk
}

\author{
Debora Jeske \\ University College Cork \\ Cork, Republic of Ireland \\ d.jeske@ucc.ie
}

\author{
Ruoyun Lin \\ Leibniz-Institut für Wissensmedien \\ Tübingen, Germany \\ r.lin@iwm-tuebingen.de
}

\begin{abstract}
The current study examined the extent to which narcissism influences the social network users' intention to share positive and negative life events with (close or unknown) online contacts. Using an online survey, small vignettes and a cross-sectional convenience sample of 119 participants, the results showed that narcissism positively predicted sharing intention of positive and negative life events with strangers. However, individuals rating higher in narcissism were less likely to share negative news with family. The research findings suggest that personality traits such as narcissism, the type of contacts online, and the nature of the news may shape what information is shared by online users. The type of news presented may therefore be a function of who is posting the content, their personality, and the kind of social network contacts they have online.
\end{abstract}

Narcissism. Social network sites. Information sharing intention. Narcissism. News sharing.

\section{INTRODUCTION}

Technology allows us to share events and news with many audiences. Researchers have investigated why and how social network users disclose information about personal life events (Bevan et al., 2015; Rozzell et al., 2014). Understanding why individuals share personal information with others on social network sites has led to research which explores motives for using these sites, such as the need for self-documentation self-presentation, building and maintaining social relationships (Carpenter, 2007; Krishan and Atkin, 2014) as well as attention-seeking and information sharing (Ahadzadeh et al., 2014; Marshall, Lefringhausen, and Ferenczi, 2005).

Several factors should be considered when investigating how information is shared, including discloser personality (e.g., narcissism, extraversion), disclosure content (i.e., positive and negative information about romantic relationships, health, school/work; see also Buckley et al., 2014), and disclosure recipients (who can read the disclosed information, such as friends, family, colleagues). Several knowledge gaps still exist in this area. First, there is little research on how personality influences the sharing of personal life events on social network sites (Krishan and Atkin, 2014). A number of variables have been investigated in terms of their general influence on social network use (see Ahadzadeh et al., 2014; Mehdizadeh, 2012; Ross et al., 2009). However, only in one case has a trait also been examined in relation to positive and negative health news sharing, namely self-disclosure (Bevan, Gomez, and Sparks, 2014).

In the current study, we focused on narcissism and the role of this trait in relation to sharing news. Narcissism describes a tendency to have an overly positive self-image that is complemented by attention seeking and egoistic admiration of one's own attributes and attractiveness (Marshall et al., 2005; Campbell and Foster, 2007; Vazire et al. 2008). This trait predicts self-promotion activities (Carpenter, 2007; Winter et al., 2014) such as being more active online and posting frequent status updates (Mehdizadeh, 2012; Winter et al., 2014) and posting more self-focused tweets (McKinney, Kelly, and Duran, 2012). Those rating high on narcissism are not necessarily perceived as favourably and as positively as they view themselves, not even by close others (Park and Colvin, 2014). These characteristics can have a negative influence on the ability of these individuals to maintain healthy interpersonal relationships (Morf and Rhodewalt, 2001).

The flipside of this trait is that more narcissistic individuals may be particularly hesitant to share negative news about themselves, as doing so would undermine their effort to be admired. Even considering that sharing negative news about oneself may get them attention, this attention may 
be based on pity. This may be an outcome incongruent with the overly positive self-image more narcissistic people construct of themselves. These circumstances suggests that individuals who score higher in narcissism will engage in significant news sharing when the news are positive, but refrain from any news sharing that may put them in a less favourable light.

Second, though it is intuitive to assume that the nature of a specific life event (disclosure content) plays a role in interpreting the likelihood of sharing, it is still unclear how personality may interact with content. Bevan et al. (2014) has investigated the relationship between sharing important life events and an individual's level of stress. The research focused on the disclosure of positive vs. negative health news on Facebook.

And third, we know little about how online contacts influence the sharing of personal life events. Individuals who disclose information have a choice over what they wish to share, and often with whom (e.g., Facebook but not necessarily on Twitter). Social penetration theory indicates that a relationship begins with the exchange of superficial information, and then gradually moves to intimate information (Altman and Taylor, 1973). This suggests that individuals may prefer to share intimate news with close others that can offer them emotional support in traditional face-to-face conversation. Some evidence suggests that social networks allow users to reach and gain support from both close and more distant connections (Rozzell et al., 2014). Social network technologies cannot only collapse multiple audiences into a single context (see Marwick and boyd, 2011), but also offer a platform for users to purposefully choose their audience.

This study aims to address these knowledge gaps by examining if narcissism influences the intention to share news about specific life events with different recipients (such as friends, family, colleagues, romantic partners, and strangers). The current study examine multiple life event categories among a student population who is actively using social networks to share news about themselves (specifically, news about health, achievement, and relationships).

\subsection{Hypotheses}

In line with evidence that narcissism is associated with a greater need to promote a positive self-image and the need to seek other people's attention, narcissism is expected to be positively related to overall sharing intention of positive life events $(\mathrm{H} 1)$. However, narcissism is expected to be negatively related to the overall sharing intention of negative life events $(\mathrm{H} 2)$. The target audience is also expected to play a role in predicting the sharing intention (contact-dependent sharing). Based on the literature, we furthermore propose that those with higher narcissism may have a stronger need for a positive self-image and will avoid damaging their positive image in the eyes of close others, reducing the sharing with these kinds of contacts compared to more distant contacts (H3). They may fear negative feedback from close others but may be less concerned about receiving negative feedback from strangers. These hypotheses will be tested using regression to control for covariates.

\section{METHOD}

\subsection{Procedure and Participants}

Following ethics approval, participants were recruited through convenience and snowball sampling via Facebook and Twitter. Participation was voluntary and not remunerated. In order to participate, the participants were required to have at least one social network account. The online survey presented the information sheet first and consent was required before participants were presented with six positive and six negative life events. For each scenario, participants were asked to select with whom they would share the information with. This was followed by a section on social media usage, personality, demographics and debrief. The study took approximately 15 minutes to complete. The survey received 165 hits. After excluding cases who did not proceed past the consent page or had missing data, the final sample was reduced to 119 participants between 18 and 53 years old $(M=$ $25.71, S D=8.31)$. This included 86 females and 24 males (9 missing values), most of which studied or came from the field of psychology/social sciences.

\subsection{Measures}

The materials and measures are described below.

2.2.1. Positive and negative life events (vignettes) The following materials were created specifically for the scale (they are not based on a standardised instrument or normative data). All participants were presented with six positive news scenarios and six negative events. These scenarios were selected from real postings found online (the content of the post was amended where necessary and users' details were eliminated to maintain confidentiality).

\subsubsection{Sharing intention}

Each scenario was followed up with the following question: "Who would you share this event with"? Answering categories were: friends, family, colleagues, romantic partner and strangers. This measure therefore considers sharing intention, not actual behaviour (see also list of events below Table 2 and 3). Participants could select all or none of these contact options per life event. The dependent measure was based on the total shares across all 
potential (5) contacts and 12 scenarios $(M=30.48$, $S D=9.15$; range 0 to 60 ).

\subsubsection{Narcissism}

Narcissism was measured using 16 items from the Narcissistic Personality Inventory (Ames, Rose, and Anderson, 2006). Participants were presented with two statements and had to select the one that reflected their personality the most. An example item including two statements is: "I really like to be the centre of attention." Statements that reflected narcissistic trait characteristics were scored as 1 , while the other statements were scored with 0 points (dichotomous coding). The greater the number of points, the higher the participant scored on the narcissism scale. All item scores were summed to create a composite narcissism score (range 0 to 16) rather than a dichotomous variable in order to capture people on the continuum. On average, participants scored relatively low on this scale $(\alpha=$ $.78, M=3.00, S D=3.04)$, which is typical of psychology students (Vedel and Thomson, 2017).

\subsubsection{Intensity of social network use}

This variable captures the degree of social network use and is considered a potential covariate. It was measured using six items from the Facebook Intensity scale by Ellison, Steinfield, and Lampe (2007). The items were modified to relate to social media generally (instead of Facebook). An example of a modified item is: "Social media is part of my everyday activity." The response options were ranged from (1) "strongly disagree" to (5) "strongly agree." Higher scores suggest higher intensity and usage of social media $(\alpha=.74, M=3.84, S D=.62)$.

\subsubsection{Demographics}

This included age and gender.

Table 1: Correlations between linear constructs and news sharing intention

\begin{tabular}{|c|c|c|c|c|c|c|c|c|}
\hline & & 1 & 2 & 3 & 4 & 5 & 6 & 7 \\
\hline 1. & Narcissism & -- & & & & & & \\
\hline 2. & Intensity & .069 & -- & & & & & \\
\hline 3. & SNS sites used & .116 & $.312^{\star *}$ & -- & & & & \\
\hline 4. & Hours on SNS & .026 & .057 & $.261^{* *}$ & -- & & & \\
\hline 5. & Number of friends & $.168^{\#}$ & .149 & $.311^{\star \star}$ & .075 & -- & & \\
\hline 6. & Time online & .096 & $.290^{* *}$ & $.304^{* *}$ & $.176^{\#}$ & .105 & -- & \\
\hline & Age & .139 & -.056 & $-.202^{*}$ & $-.175^{\#}$ & -.138 & $-.167^{\#}$ & 1 \\
\hline
\end{tabular}

Note. $N=117,{ }^{\#} p<.10 ;{ }^{* \star} p<.01 ;{ }^{*} p<.05$. Overall, 102 users used the same social network. SNS = social network.

Table 2: Sharing intention (positive life events across different contacts)

\begin{tabular}{|c|c|c|c|c|c|c|c|c|c|c|c|c|}
\hline & \multicolumn{2}{|c|}{ PS1 } & \multicolumn{2}{|c|}{ PS2 } & \multicolumn{2}{|c|}{ PS3 } & \multicolumn{2}{|c|}{ PS4 } & \multicolumn{2}{|c|}{ PS5 } & \multicolumn{2}{|c|}{ PS6 } \\
\hline & $\mathrm{M}$ & SD & M & SD & $M$ & SD & M & SD & M & SD & $\mathrm{M}$ & SD \\
\hline ..-Friends & 0.56 & 0.50 & 0.95 & 0.22 & 0.96 & 0.20 & 0.87 & 0.34 & 0.96 & 0.20 & 0.96 & 0.20 \\
\hline ..-Family & 0.86 & 0.34 & 0.85 & 0.36 & 0.97 & 0.16 & 0.71 & 0.45 & 0.99 & 0.09 & 0.97 & 0.16 \\
\hline ..-Romantic/Close Partner & 0.82 & 0.39 & 0.80 & 0.40 & 0.91 & 0.29 & 0.34 & 0.47 & 0.88 & 0.32 & 0.92 & 0.28 \\
\hline ..-Colleagues & 0.23 & 0.42 & 0.50 & 0.50 & 0.52 & 0.50 & 0.28 & 0.45 & 0.59 & 0.49 & 0.68 & 0.47 \\
\hline ..-Strangers & 0.06 & 0.24 & 0.13 & 0.34 & 0.11 & 0.31 & 0.08 & 0.27 & 0.13 & 0.34 & 0.09 & 0.29 \\
\hline Total shared & 2.53 & 1.25 & 3.24 & 1.17 & 3.47 & 0.87 & 2.27 & 1.34 & 3.55 & 0.89 & 3.62 & 0.85 \\
\hline
\end{tabular}

Note. The positive news included: (PS1) a positive health diagnosis; (PS2) completing a marathon; (PS3) getting a new job; (PS4) a new romantic relationship; (PS5) getting accepted into university; and (PS6) passing a driving test.

Table 3: Sharing intention (negative life events across different contacts)

\begin{tabular}{|c|c|c|c|c|c|c|c|c|c|c|c|c|}
\hline & \multicolumn{2}{|c|}{ NS1 } & \multicolumn{2}{|c|}{ NS2 } & \multicolumn{2}{|c|}{ NS3 } & \multicolumn{2}{|c|}{ NS4 } & \multicolumn{2}{|c|}{ NS5 } & \multicolumn{2}{|c|}{ NS6 } \\
\hline & $\mathrm{M}$ & SD & $\mathrm{M}$ & SD & $\mathrm{M}$ & SD & $\mathrm{M}$ & SD & M & SD & $\mathrm{M}$ & SD \\
\hline ..-Friends & 0.44 & 0.50 & 0.47 & 0.50 & 0.79 & 0.41 & 0.55 & 0.50 & 0.55 & 0.50 & 0.48 & 0.50 \\
\hline ..-Family & 0.83 & 0.38 & 0.71 & 0.46 & 0.62 & 0.49 & 0.73 & 0.45 & 0.76 & 0.43 & 0.73 & 0.45 \\
\hline ..-Romantic/close partner & 0.75 & 0.44 & 0.61 & 0.49 & 0.09 & 0.29 & 0.63 & 0.49 & 0.66 & 0.48 & 0.62 & 0.49 \\
\hline ..-Colleagues & 0.07 & 0.25 & 0.11 & 0.31 & 0.09 & 0.29 & 0.12 & 0.32 & 0.18 & 0.38 & 0.11 & 0.31 \\
\hline ..-Strangers & 0.00 & 0.00 & 0.06 & 0.24 & 0.02 & 0.13 & 0.01 & 0.09 & 0.03 & 0.16 & 0.02 & 0.13 \\
\hline Total shared & 2.08 & 1.11 & 1.95 & 1.31 & 1.61 & 0.99 & 2.03 & 1.26 & 2.17 & 1.34 & 1.96 & 1.31 \\
\hline
\end{tabular}

Note. The negative life events included: (NS1) a negative health diagnosis; (NS2) a health scare; (NS3) an end of a romantic relationship; (NS4) losing a job; (NS5) failing a driving test and (NS6) not getting accepted into university. In three cases (NS2, NS3 and NS4), the statement was follow up by a rhetorical remark (e.g. "what am I going to do?"). Further descriptives, when focusing on the negative items alone, suggest that negative life events followed with a rhetorical question and question mark would be shared slightly more often with friends ( $M=.60 \mathrm{vs} . M=.49)$. Including a rhetorical question did not increase sharing with family $(M=0.69$ vs. $M=0.77)$ and romantic/close partners $(M=0.44$ vs. $M=0.68)$. Differences in standard deviation eliminated these minor differences between items with and without a rhetorical question. 


\section{RESULTS}

All correlations are included in Table 1.

\subsection{Descriptive results}

Table 2 and 3 depict how likely it was that participants would share a specific type of life event with specific contacts (descriptives include the mean and standard deviation). Since the answering options were either 0 (No) or 1 (Yes), the mean generated score across all participants reflect the degree to which certain events would be shared. A mean of 1 indicates that every participant shares information about this life event with this particular type of contact. So when completing a marathon (PS3), participants said that they would be most likely to share this with friends (.95) but much more unlikely to share this life event with a stranger (.13). Participants were more likely to share positive than negative life events

\subsection{Hypothesis Testing}

The results are outlined separately for each hypothesis.

\subsubsection{Overall sharing intention ( $\mathrm{H} 1$ and $\mathrm{H} 2)$}

Hierarchical regression analyses were conducted to test our hypotheses. Significant covariates were entered in the first step, and personality traits in the second step. Narcissism was not a significant predictor of total news posting across all positive and negative life events (combined) across all contact groups together $(\beta=.014, p=.883)$, controlling for intensity of media use $(p<.01$; the result was almost identical without this covariate). These findings provide no support for $\mathrm{H} 1$ and $\mathrm{H} 2$.

\subsubsection{Contact-specific sharing intention $(H 3)$}

In terms of contact-specific sharing intention, we found that narcissism was a significant predictor of positive $(\beta=.246, p=.007)$ and negative life event posting intention with strangers $(\beta=.190, p=.038)$. This means more narcissistic individuals would share both types of news with strangers. However, narcissism was also a negative predictor of posting intention of negative news with family $(\beta=-.192, p=$ .037). This means they were reluctant to share negative news with close others but not strangers, supporting H3. No other significant results were obtained for the other contact types.

\section{DISCUSSION}

The current study focused on the role of narcissism in the sharing of life events - thus expanding on past work that explored what drives the sharing of personal news (Bevan et al., 2014). We expected that greater narcissism may lead to more withholding intention of (negative) information from close others, possibly to avoid potential social rejection (Twenge and Campbell, 2003). However, we did not find any evidence in relation to other contact types such as friends and colleagues. Future work may be able to provide more answers.

While narcissism was not a significant predictor of overall sharing intention, it was a significant (but small) predictor for specific contact-specific sharing intention. More narcissistic individuals prefer not to share negative news with family. This finding may be explained as a reflection of the need of more narcissistic individuals to obtain the attention of others and present a positive self-image (Marshall et al., 2005) via the careful and self-promoting construction of messages about one's successes (Carpenter, 2007; Mehdizadeh, 2012; Winter et al., 2014).

But in the case of strangers, more narcissistic individuals are more inclined to share negative or positive news, possibly because these contacts are not as important to their self-image and may not respond to negative news. This pattern of sharing (intention) would be in line with work that suggests people form expectations about how social network users will respond to their posts (see also Scissors, Burke, and Wengrovitz, 2016).

\subsection{Contribution, Limitations, and Future Research}

The current study focused on addressing knowledge gaps: The influence of the type of news, the contacts who receive the news, and the personality of the discloser. We therefore build upon work that examined the frequency of content posting of social network users (Scissors et al., 2016). Our results thus contribute to the limited number of studies on the reasons and outcomes of personal life events and news sharing to date (Bevan et al., 2014, 2015; Rozzell et al., 2014).

Future work may wish to remedy several limitations of the current and exploratory study. The sample included predominantly female psychology students, who may also rate lower on narcissism than other student samples (Vedel and Thomson, 2017). Although the current vignettes were based on real event examples taken from online platforms to enhance ecological validity, the posts might not be representative for the people at different stages of their life (e.g., failing a test). Negative scenarios were tested after positive scenarios in the current study (we did not use counterbalancing, and this may lead to biased results when measuring the likelihood of sharing negative life events). Furthermore, it would be useful to test actual behaviours rather than intention. Future work may wish to double-check valence of life events, sample participants' own postings, consider the role of expectations of feedback to postings, and assess how they utilise their privacy settings on social networks depending on the type of contact. 


\section{REFERENCES}

Ahadzadeh AS, Sharif SP, Wei KK, Emami H (2014) Narcissism, self-esteem, communication apprehension, and need for affiliation: Difference between social networking site users and nonusers. Taylor's Business Review, 4, 135-146

Altman I, Taylor, D. (1973) Social Penetration: The Development of Interpersonal Relationships. New York: Holt.

Ames DR, Rose P, Anderson CP. (2006) The NPI16 as a short measure of narcissism. Journal of Research in Personality, 40, 440-450

Bevan JL, Cummings MB, Kubiniec A, Mogannam M, Price M, Todd R. (2015) How are important life events disclosed on Facebook? Relationships with likelihood of sharing and privacy. Cyberpsychology, Behavior, \& Social Networking, 18, 8-12.

Bevan JL, Gomez R, Sparks L. (2014) Disclosures about important life events on Facebook: relationships with stress and quality of life. Computers in Human Behavior, 39, 246-253.

Buckley S, Hammer A, Harf A, Hepp E, Hornung, A. The direct and indirect sharing of good, important news on Facebook. Available at: http://journals.chapman.edu/ojs/index.php/mc/art icle/download/880/1027; 2014

Campbell WK, Foster JD. (2007) The narcissistic self: Background, an extended agency model, and ongoing controversies. In C. Sedikides \& S. J. Spencer (Eds.), The Self: Frontiers of Social Psychology, New York: Psychology Press, 115138.

Carpenter CJ. (2007) Narcissism on Facebook: Selfpromotional and anti-social behavior. Personality and Individual Differences, 52, 482-486.

Choi M, Panek ET, Nardis Y, Toma CL ( 2015) When social media isn't social: Friends' responsiveness to narcissists on Facebook. Personality and Individual Differences, 77, 209214.

Ellison NB, Steinfield C, Lampe C. (2007) The benefits of Facebook "friends:" Social capital and college students'use of online social network sites. Journal of Computer-Mediated Communication, 12, 1143-1168.

Krishan A, Atkin D. (2014) Individual differences in social networking site users: The interplay between antecedents and consequential effect on level of activity. Computers in Human Behavior, 40, 111-118.

Marshall TC, Lefringhausen K, Ferenczi N. (2005) The Big Five, self-esteem, and narcissism as predictors of the topics people write about in
Facebook status updates. Personality and Individual Differences, 85, 35-40.

Marwick AE, boyd, d. (2011) I tweet honestly, I tweet passionately: Twitter users, context collapse, and the imagined audience. New Media and Society, 13, 114-133.

McKinney BC, Kelly L, Duran RL. (2012) Narcissism or openness?: College students' use of Facebook and Twitter. Communication Research Reports, 29, 108-118.

Mehdizadeh S. (2012) Self-Presentation 2.0: Narcissism and self-esteem on Facebook. Cyberpsychology, Behavior, and Social Networking, 13, 357-364.

Morf CC, Rhodewalt F. (2001) Unraveling the paradoxes of narcissism: a dynamic selfregulatory processing model. Psychological Inquiry, 12, 177-196.

Park SW, Colvin CR. (2014) Narcissism and discrepancy between self and friends' perceptions of personality. Journal of Personality, 82, 278-286.

Ross C, Orr ES, Sisic M, Arseneault JM, Simmering, MG, Orr RR. (2009) Personality and motivations associated with Facebook use. Computers in Human Behavior, 25, 578-586.

Rozzell B, Piercy CW, Carr CT, King S, Lane, BL, Tornes M, \& Wright, KB. (2014) Notification pending: online social support from close and nonclose relational ties via Facebook. Computers in Human Behavior, 38, 272-280.

Scissors L, Burke M, Wengrovitz, S. (2016) What's in a Like? Attitudes and behaviors around receiving Likes on Facebook. Proceedings of CSCW'16, 27 February - 2 March, San Francisco, CA, USA.

Twenge JM, Campbell WK (2003) "Isn't it fun to get the respect that we're going to deserve?" Narcissism, social rejection, and aggression. Personality and Social Psychology Bulletin, 29, 261-272.

Vazire S, Naumann LP, Rentfrow PJ, Gosling SD. (2008) Portrait of a narcissist: Manifestations of narcissism in physical appearance. Journal of Research in Personality, 42, 1439-1447.

Vedel A, Thomson DK (2017) The Dark Triad across academic majors. Personality and Individual Differences, 116, 86-91.

Winter S, Neubaum G, Eimler SC, Gorden, V., Theil, J., Herrmann, J., Meinert, J., Krämer, N.C. )2014) Another brick in the Facebook wall - How personality traits relate to the content of status updates. Computers in Human Behavior, 34, 194-202. 